\title{
Study on Problems And Countermeasures of Low \& Medium Star Grade Tourist Hotels in Dujiangyan City
}

\author{
Denghuo Cai ${ }^{1}$, Yang $\mathrm{Liu}^{1}$ \\ ${ }^{1}$ Sichuan Technology \& Business College, Dujiangyan, 611837, China
}

Keywords: Dujiangyan City. Low \& medium star grade tourist hotel.problems. Countermeasures

\begin{abstract}
Influenced by a variety of factors, such as their own reasons, the competitive environment, national policies and April 20 Ya'an earthquake and floods and landslides in July of this year, the low \& medium star grade tourist hotel in Dujiangyan City are facing with many problems at present, and lies in the low developing period and the extremely difficult situation. Based on analyzing the current problems, this thesis aims to find the countermeasures to break through this situation.
\end{abstract}

\section{Introduction}

In recent years, especially after the May 12th Wenchuan Earthquake, the hotel industry in Dujiangyan has been developing rapidly. By the end of 2012, there are more than 1,300 various hotels in Dujiangyan City, including hotel of one five-star, one four -star, 10 three-star, one two -star, and others are economic hotels, social hostels, village hotels and rural home inns. So far, as the high -star hotels are few, so in the eyes of the locals, even three-star hotel are top-grade hotels. These top-grade hotels are not "top grade" in many aspects, but the price is much higher than that of economic hotels, therefore, they have no competitive advantages over the economic hotels. Although the hotel industry looks so flourishing, low \& medium star grade tourist hotels are facing with severe challenges.

\section{Problems}

\section{Declined operating, and severe losses}

The hotel industry in Dujiangyan City suffered heavy losses in the May 12th Wenchuan Earthquake, but after a temporary stagnation, the hotel industry returned to the development levels before the earthquake, and soon greatly exceeded the scales before the earthquake. However, But the problems immediately became apparent, people blindly rushed headlong the hotel industry as they saw the development prospect of tourist industry in Dujiangyan, resulting in serious surplus in hotel reception capacity. In the last three years, the guest room occupancy rates in Dujiangyan were below $40 \%$, especially from the second half year of 2012 to June of this year, the entire tourist industry continued to decline, and with an accelerating tendency Due to the intensifying competition, the development situation of low \& medium star grade tourist hotels became worse.

Since the October, 2012, among the 10 three-star hotels in the whole city, only one hotel supports internal reception and the operation of others are not good, even some of them are very poor. The hotels with poor operation are negotiating with other in leasing management, or contracting and selling, and the rental price is very low (haven't find the tenant). The only one two-star hotel also suffered from severe losses, and has claimed to drop out of the star-level hotels. 


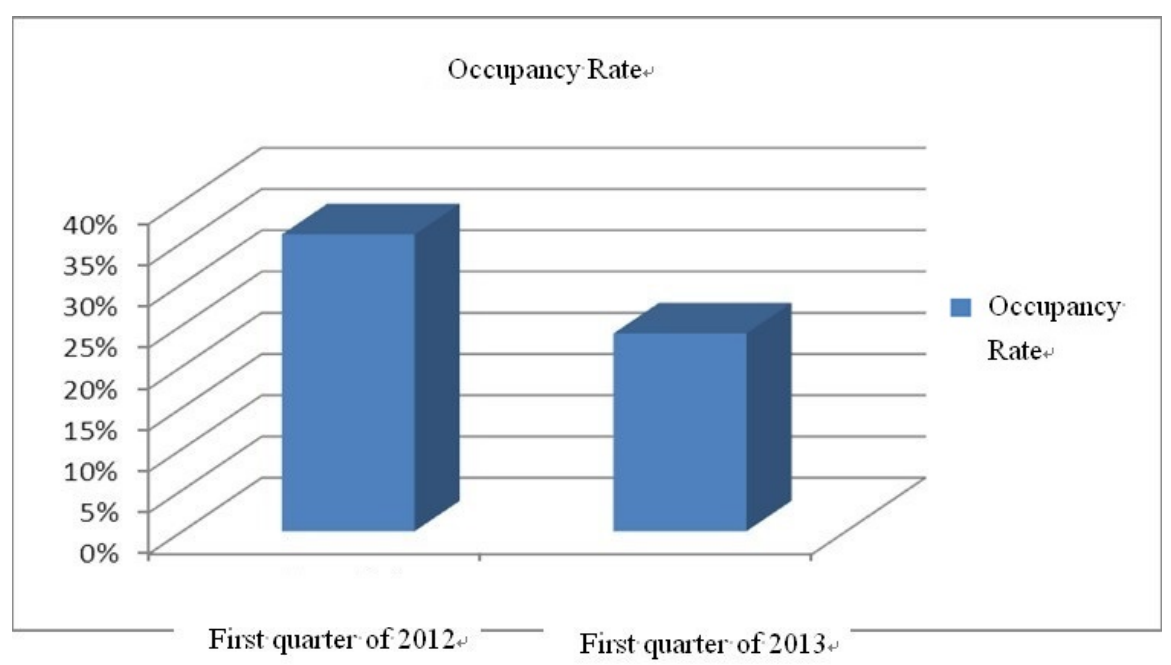

Fig. 1 Index Analysis on Occupancy Rate of Comprehensive Hotels in Dujiangyan City in the First Quarter of 2012 and 2013

Table1 The Current Operating State of the Low \& Medium Star Grade Tourist Hotels in Dujiangyan City (as of the end of November, 2013)

\begin{tabular}{|l|l|l|}
\hline Item & Number & Remarks \\
\hline Total Number & 11 & one two-star hotel, 10 three- star hotels \\
\hline Internal & 1 & profit and loss situation is not quite clear \\
\hline Number of Profitable Hotel & 0 & \\
\hline Level Off & 1 (exclude the rent) & \\
\hline Unprofitable Hotel & 9 & \\
\hline Closed Down & 1 & Equivalent to dropped out of the Star-Level \\
\hline Semi-closed Down & 1 & \\
\hline In Transfer & 1 & \\
\hline Rent-seeking & 1 & \\
\hline Partially Rent-seeking & 1 & \\
\hline Dropped out of the Star-Level & 1 & The only one two-star hotel \\
\hline
\end{tabular}

\section{High employee turnover rate, and unstable team}

Influenced by the broad environment, the above hotels are hard to survive, and thus laid off employees in succession. The annual employee turnover rate of the above 11 hotels reached over $36 \%$ in the last three years. In 2013, due to poor operation, hotels laid off employees in succession, with layoffs vary from 10-20 \%, and even reached to 40-50 \%, even much more. Some hotels are basically out of business. In order to keep staff, some enterprises in consultation with the employees in rotation vacations, which is equivalent to half layoff. State-owned enterprises can not lay off employees according to national policies and only can carry out the policy of "spontaneous reduction of staffs and do not recruit new employees”.

\section{Reason analysis}

The investigation and survey show that the main factors causing operating difficulties in the hotel industry in Dujiangyan City include:

The large scale resulted in excess of supply over demand

The May 12th Wenchuan Earthquake brought devastating blow to the tourist industry in Dujiangyan, but the ensuing post-disaster reconstruction brought great development opportunity. Within a few months after the earthquake, the original hotels reopened. At the same time, all kinds of economic hotels, inns, hotels, large and small social catering, rural hotel, rural home inns, etc. sprung up like mushrooms. In addition, the government plans to build about 15 five-star hotels in the next 3-5 years. Such a huge industry, for a tourist transit and a small city with a total population of less than 630,000 , is indeed a serious oversupply. 


\section{Influenced by financial crisis, political factors and natural disasters}

Years of global financial crisis caused economic depression in the world, and China is not an exception. The economy continued to decreasing and the hotel industry was severely affected. In addition to the new government's "eight provisions" and "six prohibitions", H7N9 avian influenza, April 20th Ya'an earthquake, especially the floods and landslides in Dujiangyan in July, etc. the tourist industry of Dujiangyan suffered a serious defeat. The supposed peak season of July, Dujiangyan tourism industry was basically at a standstill. Meanwhile the impact on hotel industry, the most vulnerable sector of tourism industry is enormous. It was anticipated that in 2013, the operation in tourism of Dujiangyan will decrease by 35-40\%, but the operation revenue of 11 low \& medium star grade tourist hotels will decrease by $60 \%$, even more.

\section{Influenced by the positioning of tourism in Dujiangyan}

The positioning of transit tour and one-day tour resulted that the hotels in Dujiangyan lost a lot of foreign tourist resources. The majority of tourists in Dujiangyan ultimately go to Jiuzhaigou Valley and Huanglong and they just pass by this city and stay a while and rarely consume in this city. It only takes one day to tour the Mount Qingcheng and Dujiangyan Dam, besides, Dujiangyan City is short of tourist experience projects and entertainment projects, thus most of the tourists do not stay overnight in Dujiangyan. In 2012, there were more than 17.3 million tourists in Dujiangyan, but less than 5\% tourists stayed overnight in Dujiangyan.

\section{Lack of government support and major marketing concept}

The development of industry is inseparable from the government's attention and support. The Government didn't issue many preferential policies to tourism enterprises in the specific initiatives, and some policies haven't been implemented completely. For instance, the government failed to implement the written reward policy for star hotels, which seriously influenced the confidence of hotel industry. The government has not come up with effective methods and measures in building overall tourism image in Dujiangyan, market exploitation, integrated marketing, etc.

\section{Influenced by internal factors}

\section{Lack of professional management team}

Professional management team is the foundation and prerequisite for hotel development, which is precisely what the hotel needs, especially the lack of professional junior and senior management personnel restricted the professional management in the hotel.

\section{Lack of distinctive and stable target market}

These hotels do not have their own distinct characteristics and well-known brands, instead, they faced with the entire market and lack of a stable target market. Therefore their business sustainability is poor, and lack of diversified competition capital.

\section{Units' and enterprises' competitive disadvantages}

The above hotels, except one hotel is managed by hotel management company, are self-established and self-supported, or hire manager from external to group manage. This kind of single operating mode lies at a distinct disadvantage place in competition with chain brands enterprises.

\section{Countermeasures}

Faced with such hard times and difficult situation, in order to break through the dilemma in low \& medium star grade tourist hotels in Dujiangyan City, the enterprises, trade association and government should make joint efforts and coordinate with each other to create a favorable development space for these hotels and even the entire tourism industry.

1). Build confidence. At present, 11 low \& medium star grade tourist hotels are suffered from different degree of operational difficulties and the enterprises are seriously in lack of confidence. But the author thinks that in the overall depressed market, confidence is the effective weapon to overcome difficulties, especially the confidence in management is a significant reassurance.

2). Accurate marketing positioning. Before October, 2012, above 60\% services in $70 \%$ of these low \& medium star grade tourist hotels in Dujiangyan City are official reception consumption, or 
consumption related to official reception (some individual hotels are complete interior reception). Due to the implementation of the new government's "eight provisions" and "six prohibitions", the operations in hotels became increasingly difficult. In this situation, enterprises should adjust their thinking, re-positioning market, target the mass consumer market, and implement differential management, which are the keys to long-term development.

3).Improve quality, increase income and reduce expenditure. Management should focus on improving quality, saving energy and cutting costs, which are the basis for reversing the situation and breaking through the dilemma. The control of human cost is not simply lower wages or layoffs, instead, it should focus on improve work efficiency. The enterprises should base on their actual situation to study the various control points in raw material costs, develop a reasonable restriction, control systems and policies. For example : form purchasing alliances with peer companies to lower the procurement costs of raw material, control the vulnerability of procurement chain, reduce or turn off projects with heavy losses, develop projects that meet the market demand, increase profits points, and so on.

4). Win-win cooperation. The low \& medium star grade tourist hotels in Dujiangyan City are similar in size, grade, feature, etc., so they can negotiate with each other and cooperate to reach mutual benefits. Establish hotel alliance with the purpose of marketing and procurement, reduce marketing and purchasing costs, and improve the effectiveness of marketing campaign. Even in the name of the alliance, the Tourism Bureau can take the lead ( or serve as a bridge) to organize the members, including enterprises of scenic spots, travel agencies, other hotels, travel commodities and others to form a larger scale of collaborative alliances to integrate high-quality resources and establish a long-term mechanism for cooperation and win-win.

5).Depend on the associations. As member units, in the face of such difficulties, should fully trust and rely on associations, and the associations should play their own advantages to solve difficulties for members. The low \& medium star grade tourist hotels can make use of their influence to help associations and government and relevant departments in communicating and coordinating, as well as help the government to play its due role to serve for the member unites. At the same time, they can also make use of the association resources to provide their staff with free training to reduce training costs.

In conclusion, The low \& medium star grade tourist hotels in Dujiangyan City are facing unprecedented difficulties, but as long as they are able to change their thinking, re-positioning, rely on government, industry associations and their own efforts, make use of a variety of superior resources, coordinate efforts to establish mutually beneficial win-win cooperation mechanisms, they can out of the woods, and meet a good opportunity in development.

\section{Acknowledgments}

This is a college-level project of Sichuan Technology and Business College of 2012, with title of Study on Development Problems and Countermeasures of Low \& Medium Star Grade Tourist Hotel in Dujiangyan City. Host: Denghuo Cai.

\section{References}

[1] Statistical Bulletin of National Economy And Social Development of Dujiangyan City in 2012, Statistical Bureau of Dujiangyan City. 2013.6.

[2] Investigation Table of the Low \& Medium Star Grade Tourist Hotels in Dujiangyan City, Sichuan Technology and Business College, 2013.11.30.

[3] Wang Jiming: Positioning and Investment Analysis on Qiaofu Hotel Project in Dujiangyan, http://cdmd.cnki.com.cn/article/cdmd-10614-2004128720.htm.

[4] Cai Denghuo Dong Ying Liu Yang: Discussion and Analysis on Business Difficulties of Hotels 
and Catering Enterprises and Their Countermeasure-Take Dujiangyan for Example, Singapore Management and Sports Science Institue, 2013 